\section{Cultural Care: Sexual Orientation As Bias In Health Care Practices}

\section{Abstract}

Background: The objective was to identify the perception of Lesbian, Gay, Bisexual, and Transgender people about the implications of non-heterosexual sexual orientation in health care practices. .

Methods: We adopted a qualitative research by conducting interviews with 30 gay and bisexual individuals recruited in the municipality of Juazeiro do Norte, Brazil, from the snowball technique in 2013. The data was categorized and analyzed based on the Theory of Diversity and Universality of Cultural Care.

Findings: It was found that sexual minorities have encountered prejudiced and discriminatory professional practices in health care as a result of heteronormative cultural representations, which reflect difficulties in accessibility to the services. The exclusionary cultural care results in poor self-care and linked to sexually transmitted diseases, low attendance and distance of health services for gay and bisexual men.

Conclusion: It is believed that the influence of heteronormative cultural conceptions in services imply deficit of self-care by the group.

\section{Keywords}

Gender; homosexuality; bisexuality; health services; culture
Grayce Alencar Albuquerque", Cintia de Lima Garcia1, Jameson Moreira Belém², Francisco Winter dos Santos Figueiredo', Laércio da Silva Paiva", Glauberto da Silva Quirino², Luiz Carlos de Abreu" ${ }^{1}$, Vitor Engrácia Valenti ${ }^{1}$, Fernando Adami ${ }^{1}$

1 Departamento de Saúde da Coletividade, Disciplina de Metodologia Científica, Laboratório de Delineamento de Estudos e Escrita Científica, Faculdade de Medicina do ABC, Santo André, SP, Brazil.

2 Programa de Pós Graduação em Enfermagem. Universidade Regional do Cariri, Crato, CE, Brazil.

\section{Contact information:}

Grayce Alencar Albuquerque, ZIP CODE: 63010-455

Tel: (055) (88)88048714

Address: 821. Príncipe de Gales Ave., Príncipe de Gales, Santo André (São Paulo), Brazil.

$\risingdotseq$ geycy@oi.com.br

\title{
Introduction
}

As a result of the struggles and social movements for the legitimization of health as a right of citizenship, health policies reinforce the importance of state action in the provision of health actions and services for the population. However, it appears that in some countries, such as Brazil, despite implementation of a national health system, the Unified Health System, much needed advance to ensure qualified 
and decisive access to services [1]. Especially when it comes to sexual minorities, like the homosexual and bisexual populations, represented by Lesbian, Gay, Bisexual and Transgender members.

Despite the principle of universality guides the Brazilian health system and ensures accessibility as a right and the resolution as a result of healthcare practices between professionals and users, making room for the diversifying of access to health services, the homosexual and bisexual population still faces resistance and barriers to legitimate the right to health just like a right of citizenship when they access health services. This because of a hostile environment in the institutions in which prejudice and discrimination by professionals and users prevails $[2$, 3, 4].

Discriminatory attitudes directed at sexual minorities result of presumption and the consolidation of a heteronormative culture, pointing at heterosexuality as universal and synonymous with normality. Soon, all that escapes this pattern, such as homosexuality and bisexuality, is regarded as abnormal and deviant $[5,6]$. Due to this situation, there are gaps in health care provided to this public, given the heteronormative cultural context in which professionals fall, resulting in inconsistent and unsatisfactory given attention $[7,8]$.

This way, the (re) cognition of homosexual and bisexual orientation of a user may appear to be a bias in care practices, since, during the offered assistance, health professionals adopt prejudiced and discriminatory behavior, which prevents them from providing the customer a holistic and humane care.

These "biases" influence the trials and decisionmaking, since, circumstantially, health professionals can assist homosexual and bisexual patients how heterosexual, based on personal and cultural assumptions that reinforce prejudice and discriminatory attitudes [9], rather than being guided by evidence-based practice, respecting the uniqueness and sexual diversity.
Therefore, it is worth remembering the previous judgment of the association between homosexuality and HIV infection, a condition that may constitute a "bias" of assistance. This collective cultural construction began in the 1980s, with the advent of AIDS, initially called gay-related immune deficiency by physicians [10], during which the public and the media reported the terms "gay cancer", "gay plague" and "pink plague". The "skewed" combination results in negative impacts on the health of sexual minorities, which, by absorbing the cultural construction, build their health representations, associating health care solely on the prevention and treatment of sexually transmitted diseases.

Biases in care, prejudiced attitudes, discriminatory and exclusionary, after the knowledge of the sexual orientation of the homosexual and bisexual individual, imply reduction in attendance, not seeking health services and self-care deficit [11, 12, 13], which increases the susceptibility of the group to health hazards.

Therefore, the issue in question is relevant as it can contribute to a better understanding of the relationship between care practices by health professionals as a result of cultural patterns, and their implications for care practices in health of sexual minorities in the face of assumed sexual orientation. The intensification of this discussion may influence the identification of risk situations and health hazards to which the Lesbian, Gay, Bisexual and Transgender group is exposed, since, from a multidisciplinary perspective, the gaps for the care directed to this population can be replaced by health actions that address the specifics of the group and sexual diversity. This work aimed to identify the perception of Lesbian, Gay, Bisexual and Transgender about the implications of non heterosexual sexual orientation in health care practices. 


\section{Theory of Diversity and Universality of Cultural Care}

It is known that care, as a cultural practice, considers the behaviors, values and beliefs of individuals and groups who care and who receive care [14]. This way, care figures as a determinant of care between professionals and users, that is, as a condition of health [15].

The health care universe is related to cultural factors that interrelate in the health-disease process [16]. This way, it is interesting to analyze how the culture in which operate health workers, as subjects of care, interferes with the care provided to sexual minorities. In this sense, the Theory of Diversity and Universality of Cultural Care of Leininger becomes appropriate for this analysis.

That theory, better known as Cross-Cultural Theory was proposed by Madeleine Leininger in 1985 as a way to support nursing care $[16,17,18]$, however, it may be extrapolated to the universe of health care services provided to the population by other professionals. The theory contains five concepts that should be pondered for its understanding: culture, worldview, environmental context, and health care [17].

The term "culture" refers to the beliefs and cultural values that are shared and transmitted from generation to generation. The worldview is the way people look and observe the world, building a value attitude about it. The environmental context is characterized as the totality of knowledge, which gives meaning to the human experience, in association with social interactions and physical, emotional and cultural dimensions. Health and care are interrelated, since these terms are cultural results, based on values, beliefs and standard ways of life, subjectively and objectively learned [16].

Recognizing the complexity of culture and its consequences, produced cultural stereotypes of Lesbian, Gay, Bisexual and Transgender people harm a holistic care and reinforce discrimination messages, which leads to inadequate health practices of professionals as a result of the heteronormative culture, the prejudiced worldview towards homosexuals and bisexuals, the discriminatory environmental, fragmented health care and of non holistic health.

This way, the introduction and discussion of the concepts inherent in Transcultural Theory, and its consequences on the health care of sexual minorities can raise more critical and reflective capacity for health professionals, educational institutions and management of services to face the socially imposed cultural standards and have repercussions in an exclusive way, in the service of homosexuals and bisexuals, can ensure this way a nondiscriminatory, humanitarian and free of damage service.

\section{Methods}

This was a qualitative study that sought to interpret and evaluate the experiences of Lesbian, Gay, Bisexual and Transgender people from the interviews, for the health care practices received by professionals and adopted for self-care.

\section{Setting and sample}

The study was conducted in the city of Juazeiro do Norte, located in the southern region of the State of Ceará, Brazil, during the year 2013, with gay and bisexual men, contacted by telephone, from the indication of the director of the association Support Group for Free Sexual Orientation of Cariri, which was configured as key informant to mediate access and recruitment of research participants through the snowball technique (chain of informants) [19].

During telephone contact, we proceeded to a brief explanation about the research and an invitation to participate. After telephone consent for inclusion as research subject, there was scheduling of the date for the meeting, according to the avai- 
lability of the participant. During the meetings, all participants were assessed for inclusion criteria: be older than 18 and have already undergone seeking health services at least once in their life.

Recruitment occurred until obtaining the saturation of the data. Thirty members were recruited and had met the inclusion criteria, being asked to sign a Informed Consent Statement to participate in the research.

\section{Data collection}

Semi-structured interviews were conducted at the homes of the participants in the months from May to July 2013. The interviews were recorded on digital audio and counted 50 hours of recording. On average, each interview lasted 90 minutes. The interview guide contemplated 15 questions relating to selfcare and therapeutic itineraries in health services.

The interviews were closed after identification of the theoretical saturation point. To guarantee anonymity, were adopted codes to identify the participants, from the characterization of sexual orientation and age.

All interviews were transcribed by an experienced transcriber and were not returned to participants for listening and verification.

\section{Data analysis}

The transcribed data was grouped according to the qualitative content analysis of Bardin, operationalized in three stages: pre-analysis; exploration of the material; and treatment of results and interpretation [20]. The grouping was conducted independently by two coders, who maintained regular contact. After consensus of the formation of categories, we proceeded to the analysis of data from the Theory of Diversity and Universality of Cultural Care [17].

\section{Accuracy}

To ensure the accuracy of qualitative data, the involved researchers had no previous contact with the previous study participants. The option for independent encodings sought to ensure the legitimacy of the data and their interpretation. To evaluate the safety of the process, regular meetings between the encoders were performed.

\section{Ethical considerations}

The research is part of a larger study, entitled Right to health: implications of homosexuality as a challenge to public health policies and access to services, submitted and approved in resolution 200.935 of 20 February 2013, by the Research Ethics Committee the Faculty of Medicine of $A B C$, following the principles of Resolution 466/12 of the National Health Council.

\section{Results}

\section{Characteristics of the study participants}

The study included 30 gay and bisexual individuals in maiority in the age group between 38 and 42 years of age ( $n=11 ; 36.6 \%)$, predominantly mixed races $(n=12 ; 40 \%)$, single $(n=22 ; 73.3 \%)$ and education higher than high school ( $n=17 ; 56.5 \%)$.

With respect to sexual orientation is $70 \%$ autoidentified themselves as gay, as Lesbian $20 \%$ and $10 \%$ as bisexual. Of the total of gays, $30 \%$ were characterized as transvestites. $80 \%$ of the participants had male biological sex and of these, 53.3\% were male gender identity.

As for career, most (80\%) reported exercising any paid activity, and three research participants (12.5\%), self-defined as transvestites, reported working as sex workers. The monthly income concentrated between one ( $R \$ 724.00)$ and two minimum wages ( $R \$ 1,448.00$ ), although there was supplementary income to $23.3 \%$ through welfare benefits of the Federal Government, especially the Bolsa Família Program.

When asked about the health care received by health professionals and for the self-care practi- 
ces, the results showed that the heteronormative cultural patterns have resulted in inadequate care practices by professionals, with negative impacts on the quality of care delivered to homosexuals and bisexuals, thus contributing to the distancing of this population of health services and self-care deficits.

The speeches made during the interviews allowed the development of four thematic categories, analyzed and discussed in association with the literature, through the application of the Theory of Diversity and Universality of Cultural Care: (1) Health professionals and users; prejudicial practices as obstacles to access to services; (2) biased care practices in health; the association with HIV infection, (3) Discriminatory assistance as bias for selfcare: the search for health services for treatment and prevention of HIV; and (4) Needs for changes biased: expansion of infectious diseases services and condom distribution.

\section{Health professionals and users: prejudicial practices as obstacles to access to services}

The reception that health services offered to users was crucial to the search for assistance. In this sense, homosexual and bisexual populations revealed the lack of care and the dehumanization of care in health services as a result of prejudice and discrimination against workers.

Homosexual and bisexual sexual orientation was identified by study participants as being responsible for the suffered prejudice while seeking health services. The transvestites reported to have suffered the most discriminatory attitudes, probably due to the feminized body image. The statements revealed that the recognition of non-heterosexual sexual orientation, even in cases of major health disorders, such as diseases, was a reason for postponement of care.
I got to the hospitals while sick, I said I was very sick and instead of them (professionals) passing me in front of the line, I kept waiting for hours and hours, I think it was prejudice, they did not care.

Transvestite, 29 y.o

One participant pointed out as to justify the postponement of health care, the fact that professionals do not wish to keep any link with patients of a minority sexual orientation, making it clear that the difficulty to obtain care is not the lack of resources, but only based on professional prejudice.

Because they (professionals) do not want to (attend to) the prejudice that still exists. They have not been able to meet, not by lack of resources, it's the barrier, prejudice.

Gay, 30 y.o.

Another participant concludes that although the health care attendance occurs, gay and bisexual patients receive an unsatisfactory service, translated into rapid and insufficient consultation for resolving the clinical condition, evidencing that the attempt of that consultation and doctor-patient relationship lasts the shortest time possible.

When you go to the posts, you spend hours there waiting, then he (the doctor) will ask you just what you're feeling, pass the recipe have to get rid of you.

Transvestite, 38 y.o.

In addition to the exclusionary and discriminatory attitudes imposed by professional, sexual minorities also revealed bias from users, embodied in comments, jokes and looks, and that implied constraints and shame towards access to services. The sample revealed difficulties in getting care in health services in view of the existence of homophobic acts by the population which is also waiting for service, which shows implicently the prejudice of the community towards sexual minorities. The looks of disapro- 
val and pejorative comments directed to the Gay, Lesbian, Bisexual and Transgender group are also mentioned as factors for not searching for health services, which implies vulnerability and health problems of sexual minorities.

Unfortunately the Lesbian, Gay, Bisexual, and Transgender have great difficulty of access to health, especially when attending the Family Health Program. The general population has difficulty (...) starts the jokes and being criticized there.

Bisexual, 37 y.o.

It happens, that when we are in the queue for a doctor, there are people who feel bad, there are some (users) begin to look a lot, we feel so awkward, and go back home, and this ends up taking the focus of what I was going to do there.

Transvestite, 34 y.o.

I have this little problem of being ashamed to go there, because everyone is staring, whispering, pointing.

Transvestite, 26 y.o.

\section{Biased health care practices: the association with HIV infection}

Gay and bisexual individuals reported low attendance in health services as a result of this bias in the assistance by professionals, who insisted on culturally associate HIV infection to the homosexual and bisexual populations.

Some participants of the study confirm the existence of a relationship between homosexuality and AIDS in the minds of health professionals, revealing that this condition is taken as a justification for the differential treatment that individuals of a sexual orientation minority receive when they access health services. This way, the relationship between sexual minorities and HIV is seen as responsible for the delay in treatment, demonstrating the existing prejudice both towards the non heterosexual sexual orientation as for HIV. The result of this exclusionary and discriminatory treatment is the deviation of sexual minorities from health services.

The health of homosexuals is even more precarious for the question that gay is a person with AIDS, AIDS is already associated to gays, gays have to be the last in line, always treated as final and through these issues many end up not going to visit health services because they will be abused by them (health professionals).

Gay, 27 y.o.

Why do doctors treat us badly? I can not understand why the homosexual already has to be branded as a carrier of an infectious disease and because he (the doctor) has to stay far from this.

Gay, 28 y.o.

\section{Discriminatory assistance as a bias for self-care: the search for health services for treatment and pre- vention of HIV}

There was, as a result of HIV association / nonheterosexual sexual orientation in services, a limited perception and a reductionist view of health of Lesbian, Gay, Bisexual and Transgender group, in defining health as not having had an STD and as "having sex with a condom."

Living well without being sick and not have AIDS.

Gay, 27 y.o.

Health is having sex with a condom.

Transvestite, 38 y.o.

Still, in order to maintain that what they consider as health, it appears that the frequency of therapeutic itineraries was directly associated with sexual practices. The search for assistance was associated with exposure to sexual risks, such as non-adoption of condoms and the possibility of sexually transmitted diseases. 
I go sometimes 3 in 3 months, or when I have intercourse without a condom, then go there to see if I have something.

Transvestite, 22 y.o.

Seeking the infectious disease Specialist, to see if I'm with an infection.

Transvestite, 31 y.o.

\section{Biased changes of needs: expansion of infectious} diseases services and condom distribution

Asked about the need for change in health services and professional care practices to meet sexual minorities, participants stressed the importance of increasing the supply of services that could ensure the attendance to sexually transmitted diseases, as well as the importance of condom distribution.

For some participants, health professionals need to expand their listening skills and provide holistic care for the individual of minority sexual orientation, by allowing clarification on sexuality and sexually transmitted diseases. The presence of a professional psychologist is also identified as being relevant.

There is still a lot to do for them (health professionals) to improve, to offer a good service for us, one needs a psychologist, professionals that guide on sexual orientation and communicable diseases.

Lesbian, 29 y.o.

We need a psychologist to help the person to deal with the disease, we need a specialist in sexually transmitted disease and there is none there. .

Gay, 23y.o.)

However others reinforce that to improve the care of health services there is a need for more resources, such as the increased supply of condoms for this audience.
I know places that don't even have condoms, and they are still discriminating, this has to improve

Gay, 43 y.o.

\section{Discussion}

This study examined the experiences of Lesbian, Gay, Bisexual and Transgender people in health services as a result of the cultural implications for professional care practices of the area and its developments in the self-care of the group.

When analyzing the discourses present in the four categories, the implications of heteronormative culture are evident, i.e. a prejudiced world view and a discriminatory environmental context, which focuses on the homosexual and bisexual population. Cultural practices in health insist on the association homosexuality/bisexuality and HIV infection, which leads professionals to act in this perspective of assistance to the group. This biased practice results in restricted self-care for sexual minorities towards sexually transmitted diseases, especially HIV. In the perception of the group, the search for health care is directed to the control and prevention of the virus. For gay and bisexual men, being healthy is not to be infected by this disease, and to have health services that give the means to not contract it and to treat it.

When it comes to the health of populations in conditions of vulnerability and its relation to sexual orientation, there is influence of standards of care due to a heteronormative, sexist and macho culture that focused on gender binary (man and woman) guided socially in the form of prejudice and discrimination towards sexual minorities.

Much of the problems in health faced by homosexual and bisexual population result from the inability of health professionals to discuss parameters linked to relationships and behaviors of individuals with homoerotic practices, since there remain culturally ingrained traditional views of gender, about 
male and female roles, in the conduct of these profissionals [21].

The constructed cultural and traditional views point to the assumption that all users of health services [30]. Are heterosexual, given the heteronormativity that is imposed as a hegemonic standard and influences the professional conduct [22]. This condition implies heteronormative and negative attitudes, while providing care to homosexual and bisexual individuals, with a strong tendency to reduce the quality of care and reinforce social stigma and homophobia [21].

Homophobia is defined as rejection, fear and irrational intolerance of non-heterosexual individuals $[1,23]$, and the social stigma reinforces the speeches and the culture that homosexuality and bisexuality, as being deviant sexual orientations, are associated with promiscuity and HIV infection [24,25]. This cultural association implies the provision of assistance in health focuses on prevention and treatment of infection, and encourages the homosexual/bisexual to associate culturally that being healthy is not having AIDS, and needing services and health professionals is synonymous with condom distribution and availability of visits with infection professionals and psychologists.

In fact, it is observed that some professionals inadvertently continue to pathologize and to stereotype gay and bisexual users, giving them the condition of patients and AIDS bearers. The majority have been restricting themselves, for health interventions, to implement actions to reduce sexual risks specifically thise related to HIV [26], within a curative logic, assistance focused on disease and not in health promotion $[27,28]$.

As a result of such lines of conduct, it appears that the care practices from professionals suffer from cultural conflicts [29]. These represent the largest clash between health professionals and homosexuals and bisexuals users, since taking care of "difference" can result in the fragmentation of the individual and at predetermined judgments, which imply a burden for sexual minorities, because they have a discriminatory environmental context and that interferes with the search for health services.

This way, in the ambience of health care, given the heteronormative culture and prejudiced worldview, the association between AIDS and homosexuality/ bisexuality becomes common, socially reinforced and able to interfere in the environmental context of professionals and users, resulting in discriminatory behavior in healthcare services, distance from the homosexual and bisexual population, as a result of the institutional violence suffered [31].

In addition to predetermined judgments, it was observed the presence of constraints, pejorative connotations and exclusionary acts directed at the Group [6] by professionals and service users, which demonstrated that the aversion to sexual minorities in the social environment, becames commonplace fact, since other studies also reveal prejudice and discriminatory messages. In a study of health professionals, the participants considered the homosexual and bisexual population as a group of sick people, not worthy to formalize marriages or even adopt children [5]. Research conducted with 116 health students, 8-12\% said that homosexuality should be punished, 5-12\% disliked sexual minorities and $51-53 \%$ that homosexuality was against their religious beliefs [32].

In consensus with top-level professionals, the general public also expressed their prejudice against sexual minorities. A survey held in 102 Brazilian municipalities, with a sampling of 2,363 individuals, found that $89 \%$ were against male homosexuality and $88 \%$ against Lesbianism and bisexuality in women [33].

In short, analyzing the implications of non-heterosexual sexual orientation as a bias to the care practices among health professionals towards homosexual and bisexual members in the light of Transcultural theory, it appears that the heteronormative culture, prejudiced worldview and the discriminatory envi- 
ronmental context result in a fragmented and curative care, and a weakened and unholistic health directed to the group. The consequences of this condition have an impact on a culture of sexual minorities which strengthens the association between health and absence of disease (HIV), a worldview that points at risk for sexually transmitted diseases, a violent environmental context in institutions, a health care based on treatment and prevention of sexual diseases, and health with high incidence of other diseases.

The adaptation of the Sunrise Model inherent in Transcultural Theory (Figure 1) illustrates the implications of cultural care of health professionals in the perception of health and self-care of Lesbian, Gay, Bisexual and Transgender people.

Figure 1: Adaptation of the Sunrise Model. Factors and elements that determine the relationship between homosexuality/ bisexuality and therapeutic routes in health, with emphasis on professional care in health and its implications in self-care with members of Lesbian, Gay, Bisexual, and Transgender communities.

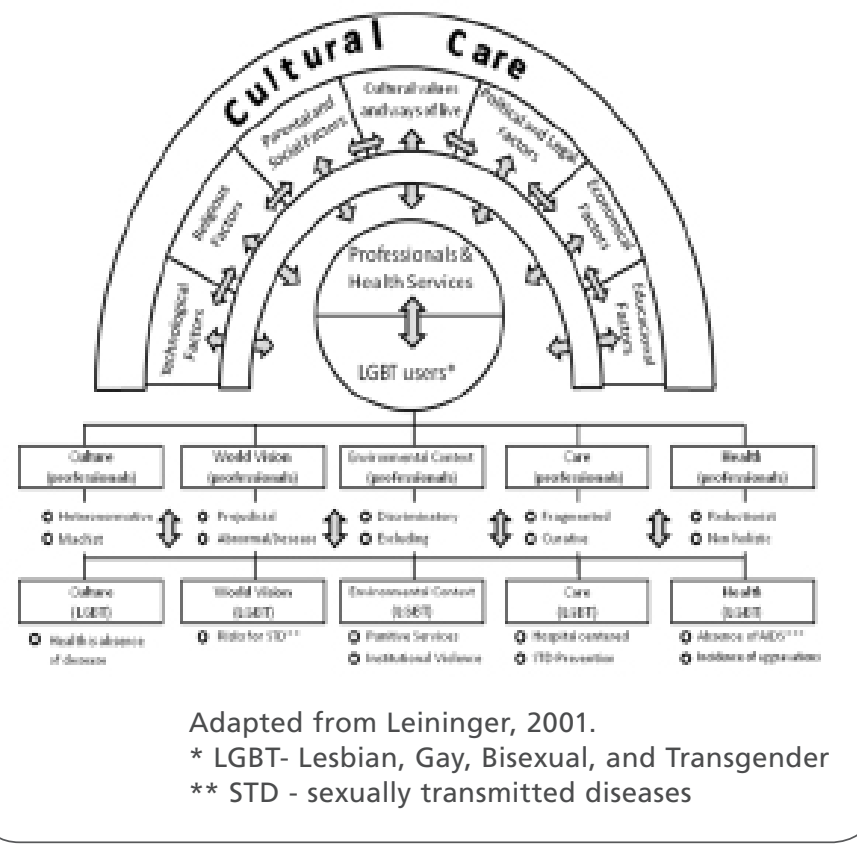

To change the current situation, it is essential to invest in training focused on developing communication skills and capabilities so that health professionals are able to offer humanized care and quality, focused on the health needs of this population and, if necessary, refer them adequately to other services, always using non-discriminatory language and approaches [22].

The need for health professionals awareness of the non-discriminatory care of homosexual and bisexual population is identified by study participants as being essential for the transformation and redefinition of concepts and care practices directed at sexual minorities, aiming to offer a humanized care, holistic and qualified health services [31].

This way, there is the need to expand the academic debate by including in the curriculum guidelines of educational institutions, the issues of gender and sexual diversity, in order to make the knowledge and culturally grounded professional practices, respected, planned and operationable [26].

It is essential that health professionals can understand the sociocultural implications in the health and disease process of this community and, from that perception, expand the focus of actions beyond the biological dimension of the individuals.

\section{Limitations}

Some limitations of the study can be identified. Due to its qualitative feature, it does not allow generalization of the results. Events can not have happened as reported, since some are not current memories. Although such limitations are present, we are confident that the experiences of dissatisfaction of the LGBT population during health care services is real, in view of the cultural base of the professionalsof the area. We point, as a reason for the credibility of the data, to the saturation process, which took place with 30 participants, a higher number when compared to values of other qualitative studies. 


\section{Conclusion}

The heteronormative culture can be considered as a bias for health care practices, predetermining judgments and decision-making for professionals and resulting in changes in the perception of health and self-care of the homosexual and bisexual population.

In this sense, the importance of culture and its consequences on the health of social groups gains strength. Therefore, the Cross-Cultural Theory became suitable as a conceptual model to justify, from its precepts, the implications of heteronormative culture in care practices in health professionals and its consequences for self-care of the Lesbian, Gay, Bisexual, and Transgender group.

Therefore, we conjecture about the need to contextualize the cultural care in the formation of these professionals in conjunction with ongoing education policies in health, humanization and promotion of equity implemented by the national health system, in order to legitimize the equal, universal, resolute, timely, not biased access and with quality to the Lesbian, Gay, Bisexual and Transgender group.

\section{Contribuintes}

Grayce Alencar Albuquerque is the principal investigator on the study and contributed to a substantial portion of the writing and interpretation of results for this paper.

Cintia de Lima Garcia conducted a significant portion of the background research for this paper and also contributed to writing.

Jameson Moreira Belém conducted a significant portion of the background research for this paper and also contributed to writing.

Francisco Winter dos Santos Figueiredo conducted a significant portion of the background research for this paper and also contributed to writing.

Laércio da Silva conducted a significant portion of the background research for this paper and also contributed to writing.
Glaubero da Silva Quirino participated in interpretation of the results and writing the final manuscript.

Luiz Carlos de Abreu participated in interpretation of the results and writing the final manuscript.

Vitor Engrácia Valenti participated in interpretation of the results and writing the final manuscript.

Fernando Adami contributed to this paper through conceptualization, data analysis and writing.

All authors have reviewed and approved the final manuscript.

\section{Conflict of interests}

The authors declare that there are no conflicts of interest.

\section{Financial support}

This study received no funding.

\section{References}

1. Lionço T. What do health rights mean for the GLBT population? Considering human, sexual and reproductive rights in the search for equity and integrality in the health system. Saúde e Sociedade. 2008; 17 (2): 11-21. doi.: 10.1590/S010412902008000200003 Available at: http://dx.doi.org/10.1590/ S0104-12902008000200003

2. Nakamura N, Zea MC. Experiences of Homonegativity and Sexual Risk Behaviour in a Sample of Latino Gay and Bisexual Men. Culture, Health e Sexuality. 2010; 12 (1): 73-85. doi.: 10.1080/13691050903089961. Available at http://www.ncbi. nlm.nih.gov/pmc/articles/PMC3646569/?report=reader

3. Moscheta MS, Santos MA. Inclusion and the challenge to create colaborative forms of nvestigation: an experience report. Saúde e Transformação Social. 2010; 1 (1): 154-9. Available at: http:// incubadora.periodicos.ufsc.br/index.php/saudeetransformacao/ article/view/415/447

4. Zanardo BVS, Andrade SMO. Reflexões sobre as diversidades sexuais na saúde: uma revisão de literatura. Revista Pitágoras. 2013; 4 (4): 2-12. Available at http://www.finan.com.br/ pitagoras/downloads/numero4/reflexoes-sobre-as.pdf 
5. González MLLS, Licona NEA. Normalización del discurso homofóbico: aspectos bioéticos. Acta Bioethica. 2006; 12: 211-7. doi.: 10.4067/S1726-569X2006000200010 Avaliable at http://www.scielo.cl/scielo.php?script=sci_arttextepid=S1726569X2006000200010

6. Orel NA. Investigating the Needs and Concerns of Lesbian, Gay, Bisexual, and Transgender Older Adults: The Use of Qualitative and Quantitative Methodology. Journal of Homosexuality. 2014; 61 (1): 53-78. doi.: 10.1080/00918369.2013.835236. Available at http://www.ncbi.nlm.nih.gov/pmc/articles/PMC4186699/

7. Kerker DB, Mostashari F, Thorpe L. Health Care Access and Utilization among Women Who Have Sex with Women: Sexual Behavior and Identity. Journal of Urban Health. 2006; 83 (5): 970-9. doi.: 10.1007/s11524-006-9096-8. Available at http:// www.ncbi.nlm.nih.gov/pmc/articles/PMC2438586/

8. Araújo MAL, Saraiva MMM, Galvão MTG, Albuquerque AD. The health professional-user relationship: experience of a homosexual woman in a renowned Fortaleza health unit. Escola Anna Nery Revista de Enfermagem. 2006; 10 (2): 323-27. doi.: 10.1590/ S1414-81452006000200022 . Available at: http://www.scielo. $\mathrm{br} /$ scielo.php? pid=\$1414-81452006000200022escript $=$ sci_ arttext

9. Steele LS, Tinmouth JM. Regular health care use by Lesbians: a path analysis of predictive factors. Family Practice. 2006; 23 (6): 631-6. doi.: 10.1093 / fampra / cml030. Available at: http:// fampra.oxfordjournals.org/content/23/6/631.long

10. Terto JRV. Homossexualidade e saúde: desafios para a terceira década de epidemia de HIV/AIDS. Horizontes Antropológicos. 2002; 8 (17): 147-58. doi.: 10.1590/S010471832002000100008. Available at: http://www.scielo.br/scielo. php?script=sci_arttext\&pid=S0104-71832002000100008\&Ing $=p t \& n r m=i s o \& t \mid n g=p t$

11. Gutiérrez NIM. Homosexual situation of sexual and reproductive health, homosexual men and women Hospital María Auxiliadora. Revista Peruana de Obstetricia y Enfermería. 2007; 3 (1): 2-16. Avaliable at: http://revistas.concytec.gob.pe/pdf/rpoe/v3n1/ a02v3n1.pdf

12. Heck J, Randall V, Gorin SS. Health care access among individuals involved in same-sex relationships. 2006; American Journal of Public Health, 96 (6): 1111-8. doi.: 10.2105/AJPH.2005.062661. Avaliable at http://www.ncbi.n/m.nih.gov/pmc/articles/ PMC1470619/

13. Matebeni Z, Reddy V, Southey-Swartz I. I thought we are safe: Southern African Lesbians' experiences of living with HIV. 2013; Culture Sexuality e Sexuality, 15 (0): 34-47. doi.: 10.1080/13691058.2013.764016. Available at: http://www. ncbi.nlm.nih.gov/pmc/articles/PMC3696027/
14. Moura MAV, Chamilco RASI, Silva LR. A teoria transcultural e sua aplicação em algumas pesquisas de enfermagem: uma reflexão. Escola Anna Nery Revista de Enfermagem. 2005; 9 (3): 434-40. doi.: 10.1590/S1414-81452005000300012. Available at: http://www.scielo.br/scielo.php?pid=S1414$81452005000300012 \&$ script=sci_arttext

15. Buss PM, Pellegrini-Filho A. A saúde e seus determinantes sociais. Physis. 2007; 17 (1): 77-93. doi.: 10.1590/S010373312007000100006 Avaliable at http://www.uff.br/coletiva1/ DETERMINANTES_SOCAIS_E_SAUDE.pdf

16. Leininger M. Ethnography and ethnonursing: models and modes of qualitative data analysis. In: Leininger, M. 1998. Qualitative research methods in nursing. Detroit: Grune e Stratton. p. 3371.

17. Lenninger M. Towards conceptualization of transcultural health care systems: concepts and a model. In: Leniniger, M. Culture care diversity and universality: a theory of nursing. 2001. New York: National League for Nursing Press. p. 53-74.

18. McCrae N, Mayer F. The role of nurses in tackling female genital mutilation. International Journal of Nursing Studies. 2014; 51 (6): 829-32. doi.: http://dx.doi.org/10.1016/j.jinurstu.2013.07.004. Available at: http://www.journalofnursingstudies.com/article/ S0020-7489(13)00218-6/fulltext

19. Semaan S, Lauby J, Liebman J. (2002) Street and network sampling in evaluation studies of HIV risk-reduction interventions. Aids Rev. 2002; 4: 213-223. Available at: http:// www.respondentdrivensampling.org/reports/Salaam $\% 20$ Semaan\%20article.pdf.

20. Caregnato RCA, Mutti R. Pesquisa qualitativa: análise de discurso versus análise de Conteúdo. Texto e Contexto em Enfermagem. 2006; 15 (4): 679-684. doi.: 10.1590/S010407072006000400017. Avaliable at http://www.scielo.br/pdf/ tce/v15n4/v15n4a17

21. Matharu K, Kravitz RL, McMahon GT, Wilson MD, Fitzgerald FT. Medical students' attitudes toward gay men. BMC Medical Education. 2012; 12: 71. doi.: 10.1186/1472-692012-71. Available at http://www.ncbi.nlm.nih.gov/pmc/articles/ PMC3460746/

22. Carvalho LS, Philippi MM. Percepção de lésbicas, gays e bissexuais em relação aos serviços de saúde. Universitas: Ciências da Saúde. 2013; 11 (2): 83-92. doi.: 10.5102/ucs. v11i2.1837. Avaliable at: http://www.publicacoesacademicas. uniceub.br/ index.php/cienciasaude/article/view/1837

23. Jesus JG. Identidade de gênero: conceitos e termos. 2012; Brasília: Ser-Tão - Núcleo de Estudos e Pesquisas em Gênero e Sexualidade. p.12-13.

24. Scardua A, Souza-Filho EA. O debate sobre a homossexualidade mediado por representações sociais: perspectivas homossexuais e heterossexuais. Psicologia: Relfexão e Crítica. 2006; 19 (3): 482-90. doi.: 10.1590/S0102-79722006000300017. Available at: http://www.scielo.br/scielo.php?script=sci_arttext\&pid $=$ S0102-79722006000300017 
25. Gomes AMT, Silva EMP, Oliveira DC. Social representations of aids and their quotidian interfaces for people living with HIV. Revista Latino-Americana de Enfermagem. 2011; 19 (3): 485-92. doi.: 10.1590/S0104-11692011000300006. Avaliable at: http://www.scielo.br/scielo.php?pid=S0104$11692011000300006 \&$ script=sci_arttext

26. Davy Z, Siriwaderna AN. To be or not to be LGBT in primary health care: health care for Lesbian, gay, bisexual, and transgender people. The British Journal of General Practice. 2012; 62 (602): 491-2. doi.: 10.3399/bjgp12X654731. Avaliable at http://www. ncbi.nlm.nih.gov/pmc/articles/PMC3426593/

27. Silva JM, Caldeira AP. Modelo assistencial e indicadores de qualidade da assistência: percepção dos profissionais da atenção primária à saúde. Cadernos de Saúde Pública. 2010; 26 (6): 1187-93. doi.: 10.1590/S0102-311X2010000600012 Available at: http://www.scielo.br/scielo.php?pid=S0102311X2010000600012\&script=sci_arttext

28. Lara MO, Brito MJM, Rezende LC. Aspectos culturais das práticas dos agentes comunitários de saúde em áreas rurais. Revista da Escola de Enfermagem da USP. 2012; 46 (3): 67380. doi.: 10.1590/S0080-62342012000300020. Available at: $\quad$ http://www.scielo.br/scielo.php?script=sci_arttext\&pid $=$ S0080-62342012000300020

29. Rissardo LK, Moliterno ACM, Borghi AC, Carreira L. Factors of the kaingang culture which influence care for the older adult: the view of the health professional. Revista LatinoAmericana de Enfermagem. 2013; 21 (6): 1345-52. doi.: 10.1590/0104-1169.3121.2373 Available at: http://www.scielo. $\mathrm{br} /$ scielo.php?pid=S0104-11692013000601345\&script $=$ sci_ arttext\&tlng=pt

30. Mcnair RP, Hegarty K. Guidelines for the primary care of Lesbian, gay, and bisexual people: a systematic review. Annals of Family Medicine. 2010; 8 (6): 533-41. doi.: 10.1370/afm.1173 Available at: http://www.ncbi.nlm.nih.gov/pmc/articles/PMC2975689/

31. Mello L, Perilo M, Braz CA, Pedrosa C. Políticas de saúde para lésbicas, gays, bissexuais, travestis e transexuais. 2011; Sexualidad, Salud y Sociedade, 9: 7-28. doi.: 10.1590/S198464872011000400002. Available at http://www.scielo.br/scielo. php?pid=S1984-64872011000400002\&script=sci_arttext

32 Arias CA, Herazo E, Cogollo Z. Homofobia em estudantes de Enfermagem. Revista da Escola de Enfermagem da USP. 2010; 44 (3): 826-830. Available at: http://www.scielo.br/scielo. php?script=sci_arttext\&pid=S0080-62342010000300041\&Ing =es\&nrm=iso\&tlng=es

33. Almeida AC. A cabeça do brasileiro. 2007; Rio de Janeiro: Record. p. 149-174

\section{Comment on this article:}

\section{(f) in $8+\boldsymbol{S}$ P}

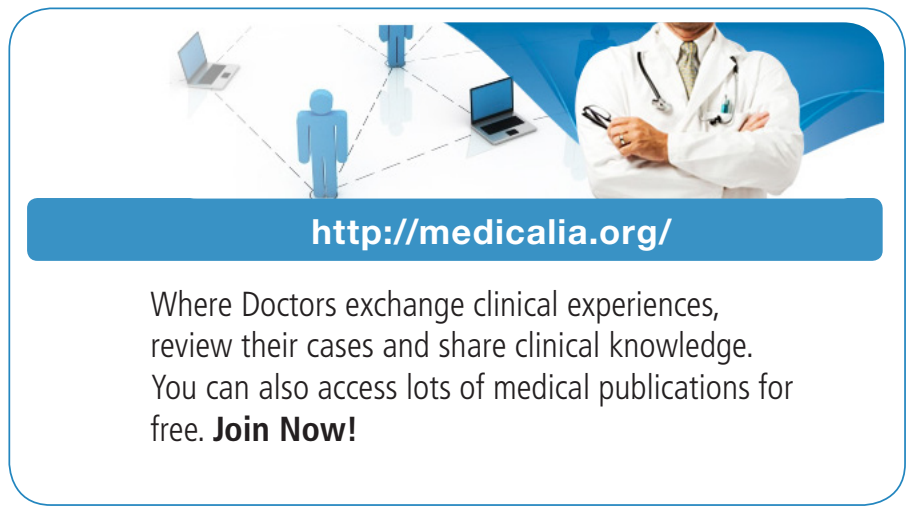

Publish with iMedPub

\section{http://www.imed.pub}

International Archives of Medicine is an open access journal publishing articles encompassing all aspects of medical science and clinical practice. IAM is considered a megajournal with independent sections on all areas of medicine. IAM is a really international journal with authors and board members from all around the world. The journal is widely indexed and classified Q1 in category Medicine. 